\title{
Cryptocurrencies, Blockchain and Regulation: A Review
}

\section{Ayesha Afzal* and Aiman Asif**}

\begin{abstract}
The evolution of money has accompanied the development of civilizations and technological innovations, leading to today's cryptocurrencies. Cryptocurrencies have become a popular mode of payment globally because of their low cost, high-speed transferability and a decentralized tracking network that provides secure transactions and a high degree of anonymity. However, the decentralized system of cryptocurrencies has made global monetary systems more dynamic and therefore more prone to misuse as well as posing a threat to financial stability. Cryptocurrencies are also gaining popularity in Pakistan: its first cryptocurrency, named 'Pakcoin', was launched in 2015. The State Bank of Pakistan does not recognize any digital currency, and the Federal Board of Revenue and Federal Investigation Agency have taken legal action against local and internationally traded cryptocurrencies. This article reviews these risks and provides various regulatory solutions so that methods can be developed to improve the management of financial innovations and create a safer environment in which financial innovation can continue. Furthermore, developing countries such as Pakistan can take advantage of distributed ledger technology (used in cryptocurrencies) in applications including: microfinance to help the unbanked, in data identification systems and in land registries to help enforce property rights.
\end{abstract}

Keywords: cryptocurrency, blockchain, regulation, Pakistan.

\section{JEL classification: G19.}

\section{Introduction}

Money has been used as a medium of exchange for about 3,000 years, following the usage of the barter system. The evolution of money has accompanied the development of societies and technological innovation, from precious stones to metal coins and paper currency. Initially, money was in the form of commodities, but as civilizations

\footnotetext{
${ }^{*}$ Assistant Professor, Lahore School of Economics, Pakistan.

** Research Associate, Center for Research in Economics and Business (CREB), Lahore School of Economics.
} 
progressed to using precious commodities and metals or stones, this led to the formation of coins (similar to those used today), typically made of gold or silver. During the Middle Ages, as people looked to goldsmiths for the safekeeping of their money, the latter started issuing receipts as a guarantee of repayment when required. Over time, these receipts became a currency that was repayable in gold or silver on presentation. This led to the development of the gold standard, where government-issued notes became trusts that could be exchanged for gold. At the turn of the twentyfirst century, further developments in currency took place in the form of emoney and virtual currencies (Davies, 2010).

Money is now classified as real, electronic and virtual, and these all exist simultaneously in the global financial system. Real currency comprises all cash or coins circulating in an economy, which have been declared legal tender by the government (Financial Crimes Enforcement Network, 2013). E-money or 'plastic money' is an extension of real currency notes, and includes credit cards, debit cards and other instruments issued by banks to simulate the exchange of real currency. ${ }^{1}$ While virtual currency does not hold the status of legal tender, it does act as a substitute for real currency and is convertible into real money (Financial Crimes Enforcement Network, 2013). Thus, it is often considered an important medium of exchange as well as an important store of value. ${ }^{2}$

Innovations in digital systems have transformed the workings of the global economy of exchange and, as a result, virtual currencies are gaining immense popularity. Cryptocurrency offers a decentralized system without an intermediary, which allows people to remain in control of managing their funds. Moreover, as currencies such as the Venezuelan bolivar are quickly losing value, cryptocurrencies have the potential to provide a better store of value than fiat currency. Cryptocurrencies are gaining increased acceptance because of their low cost, high-speed transferability and a decentralized tracking network that provides secure transactions and anonymity. Among virtual currencies, cryptocurrencies have shown faster growth and acceptability, with immense potential.

A cryptocurrency is an electronic cash system, working on a peer-topeer basis to facilitate the transfer of funds between users without a financial intermediary or central repository. These types of virtual currencies are unregulated and are not backed by any government. Their rapid growth

\footnotetext{
${ }^{1} \mathrm{http} / / /$ lexicon.ft.com/Term?term=e_money

2 After the global financial crisis in 2007/08, for instance, people who had trusted financial intermediaries such as banks were unable to recover their savings due to institutional mismanagement.
} 
presents a challenge to governments around the world, given that the wide acceptance of cryptocurrencies has the potential to disrupt regulated payment systems and affect the implementation of monetary policy. Moreover, because they promote anonymity, these currencies can be used for unlawful purposes (Middlebrooke \& Hughes, 2014).

The decentralized system of cryptocurrencies has made global monetary systems more dynamic and is thus more prone to misuse as well as posing a threat to financial stability. There is a need for governments to provide effective regulation to minimize the risks associated with this innovative payment system and to maximize its potential benefits. Cryptocurrencies are revolutionary in terms of their distributed ledger technology (DLT), which has many different applications both for the public as well as governments and public institutions. In fact, Davidson et al. (2016) argue that these may compete with various economic institutions due to their widespread applications.

Bitcoin was the first cryptocurrency launched in 2008 by an individual or group of individuals operating under the name of 'Satoshi Nakamoto'. This currency adopted blockchain technology and created a peer-to-peer payment system that ensures anonymity and transparency in transactions. Further, the technology is deemed to be practical for trade as the transactions are irreversible and can help prevent fraud through smart contracts (Satoshi Nakamoto, 2008).

This article addresses the various risks associated with an unregulated cryptocurrency market and, taking a step further, discusses possible avenues of regulation as well as applications of the technology for Pakistan.

\section{The Growth of Cryptocurrency}

Toward the end of 2017, Bitcoin was the most popular and widely traded cryptocurrency out of over 1,800 cryptocurrencies (Leong \& ChavezDreyfuss, 2018), with daily transactions in bitcoins at an all-time high of 490,000 in December 2017 (Figure 1). There are several other cryptocurrencies in the market today, some examples including Litecoins, Altcoins, Etheruem, Ripple, Auroracoins, Mastercoin, Dogecoin and Peercoin. 


\section{Figure 1: Daily transactions for Bitcoin}

Confirmed Transactions Per Day

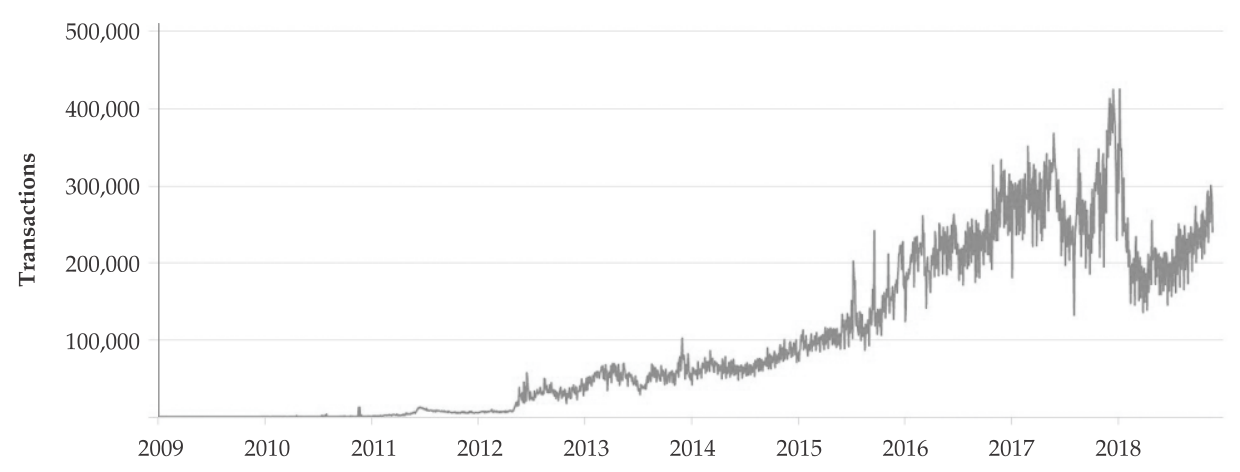

Source: Blockchain.info

As of April 2018, the total market capitalization of cryptocurrencies was over $\$ 278$ billion and the record high daily volume is larger than $\$ 500$ billion. ${ }^{3}$ Estimates suggest that between 2.9 million and 5.8 million people all around the world have invested in cryptocurrencies, with a total market value of \$27 billion (Hileman \& Rauchs, 2017). Details concerning some major cryptocurrencies are given in Table 1.

Table 1: Some major cryptocurrencies, November 2018

\begin{tabular}{lll}
\hline Currency & \multicolumn{1}{c}{ Characteristics } & Market capitalization \\
\hline Bitcoin & The first and most popular cryptocurrency & $\$ 111,667,324,912$ \\
Ripple & A currency developed for peer-based debt transfer & $\$ 21,503,755,339$ \\
Ethereum & A currency that supports smart contracts & $\$ 21,692,737,457$ \\
Swiftcoin & The first currency to be patented in the US & $\$ 8,443,833$ \\
Petro & The first oil-backed cryptocurrency & $\$ 1,872,677$ \\
\hline
\end{tabular}

Source: CoinMarketCap.com

The growing popularity of cryptocurrencies is evident from the growth in number of cryptocurrency transactions taking place, particularly in Bitcoin. Figure 2 shows that, in a short span of two years, this number has grown from about 100,000 transactions a day to over 490,000 transactions, peaking in December 2017. While the value of Bitcoin had increased due to speculation, Bitcoin prices have seen a tremendous reduction given the risks associated with cryptocurrencies. Despite this, cryptocurrency participation has been growing in emerging and developed economies including Japan, China, India and Bangladesh among other countries in the Asia-Pacific

\footnotetext{
${ }^{3}$ Cryptocurrency prices and global market cap list. https://www.livecoinwatch.com/
} 
region. There is a marked increase in the number of investors or active users as well as the employment being generated in the cryptocurrency industry, in which the number of active users has potentially reached 5.8 million.

\section{Figure 2: Bitcoin prices}

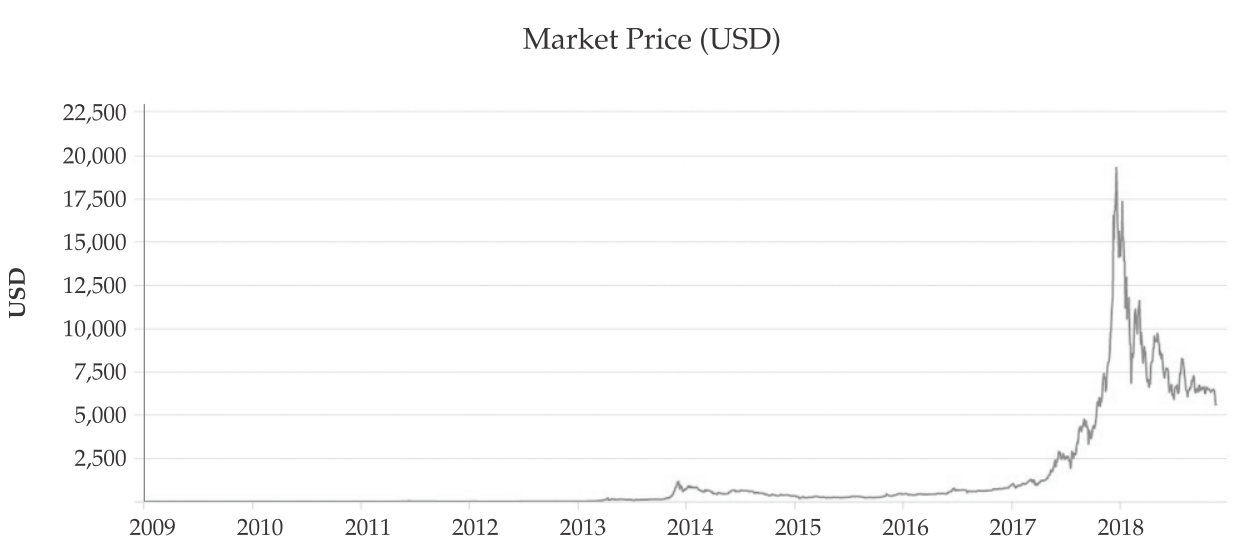

Source: Blockchain.info

The development of newer currencies such as Bitcoin cash, NEM and IOTA has advanced especially in the Asia-Pacific region, which has the highest number of people - over 700 out of 1,876-developing or employed in the sector. Moreover, the region contributes approximately 20 percent of wallet users, most of whom tend to use large wallet providers. This makes them more susceptible to changes in the global cryptocurrency market (Hileman \& Rauchs, 2017). However, given the trend of growth in cryptocurrency prices, including not only Bitcoin, but also Etheruem, Litecoin and Ripple, the number of users and the market capitalization values of all cryptocurrencies is expected to increase.

Considering the various uses of cryptocurrencies and particularly illicit transactions and the associated risks, these figures indicate the need for regulation in the industry. These currencies have made a significant contribution to people's lives, but it is important to understand that they cannot survive without appropriate legislation. The technology they have introduced has already made its mark on the world and is now prompting financial system stakeholders to look at alternatives to traditional banking for all sorts of legal and illegal transactions. 


\section{How Cryptocurrencies Work}

There are three major parties involved in any transaction pertaining to cryptocurrencies: the user, the exchanger and the issuer. Users include all entities who obtain virtual currencies to purchase goods and services or simply to transact on the network. Exchangers include all entities involved in the conversion of real currency to virtual and vice versa. Issuers and redeemers of virtual currency are the entities known as administrators (Financial Crimes Enforcement Network, 2013). A simplified version of this process is given in Figure 3.

\section{Figure 3: How Blockchain works}

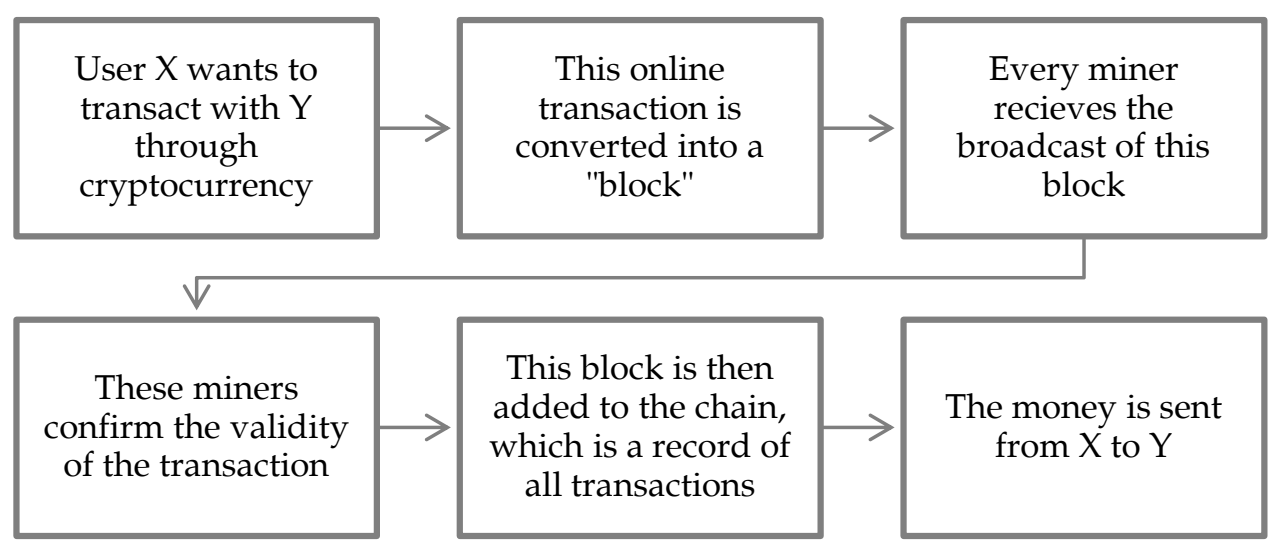

Source: World Economic Forum

Cryptocurrencies have the potential to redefine the workings of the monetary system. They promote an advanced level of technology based on blockchains and other security protocols such as CryptoNote (van Saberhagen, 2013) and SNARK (Ben-Sasson et. al., 2013). Harvey and Tymoigne (2015) emphasize the level of security provided by these networks, along with a high level of transparency.

Bitcoin, one of the most popular cryptocurrencies in the world, is based on this system. Every transaction that takes place is verified by network nodes and entered in the blockchain system, which is similar to a public ledger. This distributed network has been designed to avoid any double-spending errors. All transactions are traceable on the blockchain, providing an indisputable record. The security protocols in the electronic financial ledger prevent transaction details from being removed or altered, thus creating a complete record of all transactions involving the currency. 
Blockchain also provides a way to verify the ownership of each unit and often helps in setting up and executing smart contracts, such as those involving a transfer of title (Harvey \& Tymoigne, 2015). Smart contracts are essentially a set of instructions that can perform some level of calculations and send transactions as well as store information (Omohundro, 2014). In Ethereum, for instance, a transaction may trigger a contract, resulting in actions such as the creation of a new account (Hu et al., 2017). For each transaction, the owner provides a private key, considered a digital signature for the transaction. The corresponding public key is used to verify this signature. It is essential that the private key is not lost because it is the sole evidence of ownership that the Bitcoin network will accept. Once verified, this transaction becomes part of the blockchain. The process of verifying these transactions is performed by a miner and is called 'Bitcoin mining'. A miner is the creator of a cryptocurrency, who solves complex puzzles to create blockchains and 'unlock' virtual coins for a reward in the form of bitcoins (Financial Crimes Enforcement Network, 2013).

Cryptocurrencies provide a direct method of exchange and thus mitigate the role of the intermediary. The peer-to-peer function is advantageous in tax saving for money transfers, especially in the form of remittances. These currencies allow an improved flow of funds without loss of income in the form of payments to intermediaries or in the form of taxes. Furthermore, cryptocurrencies can recognize any digital information as an asset providing a more valid title to intellectual property. Each asset held in the digital wallet, also called an 'e-wallet', stores a transaction history. With a more valid title, given the secure nature of the Blockchain network, intellectual property theft can be reduced significantly (Tapscott \& Tapscott, 2016).

\section{Risks Associated with Unregulated Cryptocurrencies}

The growing popularity of cryptocurrencies and financial innovation carries associated risks that raise concerns for their viability and future integration in the monetary system, especially in the absence of appropriate regulation.

\subsection{Black Markets}

Fernandez (2012) finds that online roleplaying games or other interactive online entertainment sites, such as World of Warcraft, have been involved in illegal activity such as money laundering. These platforms are used to disguise criminal activities online, with an estimated value of $\$ 500$ 
million. They simulate a monetary system that is used as a front for illegal transactions, including money laundering, drug trading and child pornography (Brezo \& Bringas, 2013; Bryans, 2014).

As cryptocurrency payments move closer to replacing traditional fiat currencies, the expected value of the black economy could certainly escalate. This is primarily because transactions have become extremely difficult to trace back to the wallet owner. In some cases, such as the Silk Road system - labelled the 'Amazon of illegal drugs' - governments have taken action, as these systems were designed primarily to ensure anonymity at both ends of a transaction (Jacobs, 2011; Barrat, 2012). In this case, the European Cybercrime Centre, the FBI and other law enforcement agencies took control of all drugs, cash and other assets, and arrested all the administrators and sellers on the network. Bitcoins worth over a million dollars were also seized (Europol, 2014). An interesting development comes from prosecutors in Utah, who have decided to start selling bitcoins that were seized last year as part of a drug ring bust. The value of the seized cryptocoins was $\$ 8.5$ million in December 2017 (CNBC, 2018).

\subsection{Technology Market}

As the popularity of cryptocurrencies grows, the effects spill over into other industries as well. Blockchain technology requires graphic processing units (GPUs), including graphic cards and other power-intensive computing technology to mine cryptocurrencies and create blockchains. However, as miners look to setting up server farms, demand for the technology has caused a price surge for GPUs. Parts can sell for up to twice the suggested retail price, creating a black market for the sale and resale of computing parts required for mining and hashing (Mearian, 2018). Since NVIDIA, a GPU manufacturer, prefers retailing to gamers rather than miners, this limits the growth of blockchain technology as each new blockchain requires more power.

\subsection{Energy Consumption}

The technology involved in mining and creating blockchains is highly power-intensive: the Bitcoin network alone consumes as much energy as Austria. According to Digiconomist, the entire Bitcoin network consumes 73 terawatt-hours ( 73 million megawatt-hours) of electricity, ${ }^{4}$ whereas Ethereum's consumption is estimated at 15.92 terawatt-hours, or

\footnotetext{
${ }^{4}$ https://digiconomist.net/bitcoin-energy-consumption
} 
as much electricity as the Dominican Republic. ${ }^{5}$ This poses a problem because, as cryptocurrencies are adopted globally and prices rise to $\$ 50,000$, the associated energy consumption could increase tenfold. Even though mining technology is becoming power-efficient, as the currencies grow, energy consumption will increase to an extent that it may become unprofitable for miners (Hern, 2018). This could become a serious concern for power sectors in each country and may become unsustainable if a network grows beyond measure.

\subsection{Taxation and Tax Evasion}

On a wider level, countries such as the US, Germany and China have been among the first to take action against cryptocurrencies. Germany considered taxing cryptocurrency as a capital asset as it gained popularity in 2013/14 ('Germany plans tax', 2013). More recently, the German central bank has discouraged investment in cryptocurrencies. ${ }^{6}$ Similarly, in China, due to growing distrust of the technology, the central bank has decided to control these cryptocurrencies by banning their initial coin offerings (van Steenis, 2017). With the growing use of cryptocurrencies as payment tools, tax evasion has become a major issue for governments globally. Marian (2013) underlines two important characteristics of these currencies that facilitate illicit transactions. First, there is no cap on the number of wallets users can keep, allowing them to trade without providing any information about the owner. Second, due to the nature of the currencies, users do not rely on financial intermediaries.

Given the rapid growth of cryptocurrencies, the governments of Germany and China have tried to control them by imposing taxes and bans on initial coin offerings (ICOs) (Wildau, 2017). The US government has also made efforts in the matter by bringing these currencies under the laws for money transmitting businesses, particularly Sections 1960 and 5313 of the U.S. Code (Middlebrook \& Hughes, 2014). While some governments, including Switzerland, the EU, OECD and the US, are cooperating to eliminate offshore tax evasion, there has been a simultaneous growth in cryptocurrencies in those regions. Without sufficient regulation, cryptocurrencies and their ability to act as tax havens could entirely defeat governments' attempts at reducing tax evasion (Marian, 2013; Grinberg, 2012).

\footnotetext{
${ }^{5} \mathrm{https}$ ///digiconomist.net/ethereum-energy-consumption

${ }^{6}$ http://www.bundesbank.de/Redaktion/EN/Reden/2017/2017_09_20_thiele.html
} 
One such attempt in the US is the Foreign Accounts Tax Compliance Act, which was developed in 2010 and has been gradually implemented since 2014. It requires foreign financial institutions to report any customers who are US nationals to the Internal Revenue Service (Marian, 2013). In January 2018, Steven Mnuchin, the Secretary of the Treasury, announced that the Financial Stability Oversight Council would address the growing cryptocurrency market and work on regulations to prevent the emergence of a digital Swiss account alternative. He also emphasized that his focus was to prevent the use of these currencies for illicit transactions (Nelson, 2018).

The Canadian Securities Administrators issued a notice in August 2017 hinting that cryptocurrencies may be brought under Canadian securities legislation. However, in January 2018, the head of the central bank of Canada spoke of cryptocurrencies as being 'essentially speculative'. Canada has joined a cautionary directive as part of the North American Securities Administrators Association, whose representatives consider cryptocurrencies to be highly risky.

The European Central Bank has also moved cryptocurrencies higher up on their priorities, given the accelerating optimism witnessed in Ethereum and Ripple, among other cryptocurrencies. Several board members, including Yves Mersch, have shown concern over this surge, emphasizing that these 'very risky assets' have a significant social and psychological impact similar to that of a gold rush, but without any actual asset backing (Megaw, 2018). Mersch also discussed the possible use of cryptocurrency in funding terrorism and money laundering, highlighting that their globalization requires globalized action to be taken.

\subsection{Hacking}

The security features of cryptocurrencies employ the blockchain system with 'proof of work' puzzles (Bonneau et al., 2015), which make them immune to hacking and theft. Empirically, however, this has been proven otherwise. The Mt. Gox exchange in Tokyo experienced the 'disappearance' of about half a billion dollars' worth of bitcoins, the causes of which remain elusive. A document was circulated on behalf of Mt. Gox, claiming that this was a theft that had been ongoing for several years. However, it may also have been a failure of the Bitcoin security system. Due to the anonymity of the transactions and the ability of a single user to hold multiple wallets, such theft cannot be traced, suggesting that the system can be hacked (Wagstaff, 2014). 
Similar incidents have taken place all over the world, including Swansea, Massachusetts, in 2013 (Bray, 2015) and the Presbyterian Medical Centre in Los Angeles in 2016 (Mclean, 2016), where a virus by the name of CryptoLocker encrypted users' files, demanding ransom in bitcoins for the decryption key (Garber, 2014). This raises security concerns for those investing in cryptocurrencies (Bonneau et al., 2015).

\subsection{Speculation Bubble}

Cryptocurrencies are highly sensitive to speculation, particularly when it comes to real currency conversion. While some countries are still trying to recover from the impact of the financial crisis of $2007 / 08$, caused by a housing market bubble, little thought has been given to the potential speculative bubble that may be growing due to cryptocurrencies - the Bitcoin bubble (Maurer, 2011). Many people are now investing in cryptocurrencies, hoping to profit from speculation. However, the lack of asset backing and changes in the market or macroeconomic conditions can affect their prices significantly (Brezo \& Bringas, 2013). In short, the illiquid nature of cryptocurrencies means that the industry is highly volatile and, therefore, very risky for the economy. Bitcoin, for one, has seen immense volatility, its price having risen from $\$ 13$ in January 2013 to $\$ 1,242$ only ten months later (Hughes \& Middlebrooke, 2014).

Warnings over this matter are already being issued by regulators around the world and by investors and bankers, most prominent of which has been Jamie Dimon, the CEO of JP Morgan Chase. Moreover, Andrew Bailey, chief executive at the Financial Conduit Authority, suggests that investors should be prepared to lose all their money (Meredith, 2017). Similarly, Warren Buffet has also warned that investing in cryptocurrency is pure speculation as it has no intrinsic value (Montag, 2018). These warnings have grown significantly louder as Bitcoin reached new heights in midDecember 2017, with bitcoin trading prices crossing $\$ 18,000$. As reported by the New York Times, Wall Street companies have shown growing interest in the market, which can be credited for these price hikes (Popper, 2017).

\subsection{Volatility}

The introduction of bitcoin futures in early December 2017 has increased the risk of investing in these currencies by making the market more volatile. As suggested by Thomas Petterfy, the CEO of Interactive Brokers, this volatility could potentially cause a crisis similar to that of 2008 (Roberts, 2017). The effects of this, as well as other factors, including changes 
in investor sentiment, caused an immense decline from close to $\$ 20,000$ to around $\$ 8,000$ in bitcoin prices. Those who had bought the cryptocurrency shortly prior faced losses in the short term, given that the currency has not recovered as quickly as expected. However, experts suggest that longer-term investors are still far from the risk.

This decline has shown how volatile the currency really is, with small movements from regulators leading to a change in price and volume (Popken, 2018). For instance, the subpoenas sent to two of the largest cryptocurrency exchanges, Bitfinex and Tether, caused the Bitcoin to decline by 10 percent the same day, according to Bloomberg (Leising, 2018). However, since they do not have any asset backing and their actual number or origin is unknown, there is a very high risk of collapsing virtual currency exchanges, leading to the next global recession. This can be avoided if, unlike in 2007, regulators and governments decide to regulate the industry.

\section{Existing Regulations and Recommendations}

Zug, a small town in Switzerland, is proof that cryptocurrencies are here to stay. It has been dubbed 'Crypto Valley' and is home to over 20 virtual currency exchanges, asset managers and brokers. The town began to adopt this new system in May 2015 and now houses 12 Bitcoin ATMs (Miller, 2017). Utility bills and taxes are also being paid in virtual currencies. The Financial Market Supervisory Authority is developing licenses for businesses to be able to regulate the currency in Switzerland, although any other self-regulatory organizations can also be contacted to obtain a license.

A similar approach was taken by Bitcoin, where a self-regulatory body called the Digital Asset Transfer Authority has been established with the sole purpose of developing compliance standards and performing risk management activities (Bradbury, 2013; Middlebrooke \& Hughes, 2014). In early 2018, the Swiss economics minister, Johann Schneider-Ammann, showed interest in making Switzerland the first crypto-nation while maintaining the integrity of the financial system.

A similar trend has been observed in other countries. The Reserve Bank of Australia, for example, is now considering the 'digital Australian dollar' after pressure from FinTech Australia. These startups suggest a digital currency, backed by Australia's fiat currency, to hedge the liquidity and volatility risks of cryptocurrencies (Yoo, 2017). However, as far as other cryptocurrencies are concerned, the Australian Taxation Office passed a statement in December 2017, hinting that these may be brought 
under capital gains taxation. Estonia has completely digitized its government systems, with experts working on a government cloud storage system. Their use of blockchain technology has enabled them to prevent hacking. Moreover, with the country's Estonian ID systems, a digital currency could improve its payments systems and make them truly transparent (Lufkin, 2017).

Venezuela is seeking refuge from its economic problems in Bitcoin, where people are now looking to pay through Bitcoin for a multitude of transactions (Leary, 2017). In fact, the country might as well convert completely to Bitcoin to improve its economic situation. Venezuela has been unable to make its bond payments on time and tops the list of countries with a failing currency (Buck, 2017). The government is working on developing a cryptocurrency backed by petroleum and oil, including a registry of cryptocurrency miners, being compiled since December 2017.

Nigeria has also faced a crisis because of its fiat currency, due to which cryptocurrency trading showed immense growth. Nigeria's central bank is now being called on to make the necessary regulatory changes, as its governor, Edwin Emefield, has called these currencies a gamble, emphasizing that the government will not support such a venture. South Africa has, unlike other African countries, taken a progressive approach to the subject. The government has been working on a blockchain-based cryptocurrency to create a balanced approach to regulating these currencies (Nelson, 2018). On the contrary, Russia has emphasized the importance of regulating cryptocurrencies, but without any agreement on how to achieve this. While the finance ministry has presented a draft law, this legislation has been criticized heavily for being too stringent. However, the government has begun crackdowns on the instruction of President Putin in January 2018. Ghana has shown significant openness to the idea of cryptocurrency: the governor of the Bank of Ghana has talked of recommendations for regulating the currency, although Ghana is still one of the six countries that have banned Bitcoin.

The question of whether cryptocurrencies are merely a fad has become outdated with the growing interest of investment banks, as Morgan Stanley's CEO established (Martin, 2017). It is now time to focus on how to overcome the challenges they present through various regulations. One way is to follow the path of the US and bring the exchanges under existing laws pertaining to money transmitters and currency exchanges (Middlebrooke \& Hughes, 2014). However, the downside to such a policy is that it regulates only those users converting their virtual currencies into fiat currencies or 
vice versa. Another suggestion for regulating these currencies is to give them asset backing through gold, silver or other valuable assets.

The founder of e-gold, a failed virtual currency, is making this attempt to revive the currency and make it more secure (Middlebrooke \& Hughes, 2014; Foley, 2013). The currency was shut down in 2007 because of its involvement in illegal transactions (US Department of Justice, 2007). However, Dibbell (2002) establishes that an asset-backed virtual currency will not only help regulate it, but it will also be safer against pricing bubbles and market crashes. It is not only important to regulate the industry, but also to separate the different currencies based on their protocols. The need for this action arises because each of these brands emphasizes certain attributes, thus requiring specific attention (Middlebrooke \& Hughes, 2014). Ideally, different currencies that support similar business models should adhere to different regulatory schemes.

One approach to regulating cryptocurrencies that was adopted by the US involves bringing them under the money transmission laws. In the case of e-gold, Section 1960 of the Constitution, pertaining to money transmitters, was used to indict the company. This section defines the need for money transmitters to obtain licenses for operating, whereby any form of funds can be transferred, not just cash. This has set a precedent that defines a money transmitting business as one that includes all unconventional financial institutions (Middlebrooke \& Hughes, 2014). There is pressure for greater transparency on the cryptocurrency exchanges to regulate them better. However, while these regulate the currency administrators and exchangers, users are not regulated under this law, creating a loophole. A more comprehensive approach to regulating these currencies would be to allow central banks to purchase bitcoins. Being finite in nature, these currencies could theoretically be eliminated if governments start mining cryptocurrencies and stop them from circulating. However, this approach does not ensure that other virtual currencies will not replace them (Marian, 2013).

Similar to the joint action taken to prevent tax evasion by the governments of the US, Switzerland, EU and OECD countries, there is a need for collaborative efforts. Without this, the treatment of violators may be inconsistent, preventing policies from being effective (He et al., 2016). Yves Mersch, an executive board member of the European Central Bank, has explained how some cryptocurrencies have no national base and are not centric to one country or region. He believes that, although cryptocurrencies are not widespread enough to cause major economic disruptions, they have 
had a social as well as psychological effect similar to that of a gold rush (Megaw, 2018). To resolve this, he suggests taking globalized action whereby central authorities enforce the reporting of transactions on unregulated platforms such that the banking authorities have access to this information and can take action where necessary.

In January 2018, there were several calls for cryptocurrency regulation, including statements by the French minister, Bruno Le Maire, Bundesbank member Joachim Wuermeling, and vice-president of the European Commission, Valdis Dombrovskis. However, no regulation has been finalized or announced yet. The regulation of these cryptocurrencies still occurs in some shape, although it is not formal. Lehdonvirta (2016) of the Alan Turing Institute at Oxford explains DLT and why the technology may have little effect on the economy as a whole even though it is considered "revolutionary". He explains that third-party enforcement and governance exist in blockchain technology, particularly in the case of Bitcoin, except that the regulators are miners and programmers who have the ability not only to enforce rules but also to make those rules.

The lack of formal regulation, such as that by a banking authority, for such currencies means that the rules can be changed at any point in time, creating a bureaucracy of programmers who are free to change the rules as they please. Since the technology is not self-governed - and instead governed by a group of programmers - at the end of the day, there are still humans governing the process. Therefore, it is better to have formal structure in accordance with a legal system rather than a structure ruled over by a group of individuals without a unified goal.

In Asia, while Japan has been able to attract the cryptocurrency industry, with several crypto-exchanges and an increasing number of miners, the enthusiasm has been dampened due to Japanese exchanges being hacked: on 28 January 2018, this caused a loss of \$530 million. China, however, has banned ICOs as well as all cryptocurrency-related activity (including trading and mining) over the Internet, and strict sentences to violators. These regulatory restrictions have been imposed to prevent capital outflows from China. In January 2018, officials imposed regulation by preventing cryptocurrency trade through anonymous accounts. However, the lack of coordination between different regulatory authorities across countries presents a challenge.

Unlike other Asian countries, Singapore has shown support for cryptocurrencies, with deputy Prime Minister Tharman Shanmugaratnam 
saying that the country does not differentiate between fiat and digital currency. Moreover, the Monetary Authority of Singapore is working on Project Ubin under which various applications of blockchain technology are being researched. The motivation behind this project is to create a more efficient and low-cost alternative to monetary applications (Pollock, 2018). The government's support for the development of blockchain technologies has encouraged Singapore Airlines to develop a digital wallet that will help improve its loyalty program and make it more efficient by allowing members to register transactions through blockchain technology (Zhao, 2018). Local private sector banks are also making collaborative efforts to create a system to manage trading and logistical transactions between different parties (Gupta, 2018). Meanwhile, India has begun a crackdown against cryptocurrencies due to increased activity in the black market and illicit transactions pertaining to money laundering, terrorism and tax evasion.

Cryptocurrencies are also gaining popularity in Pakistan. Its first cryptocurrency, Pakcoin, was launched in 2015. Since 2009, payment systems have witnessed a great deal of innovation, including solutions such as Easypaisa. The popularity and growth of these systems suggests there is potential for the growth of cryptocurrencies in the country. In November 2017, the IMF chief advised Pakistan not to dismiss these virtual currencies because of consumer preferences (Husain, 2017). However, the State Bank of Pakistan (SBP) and Federal Board of Revenue have shut down the use of digital currencies in the economy. The SBP (2016) does not recognize any digital currency. A circular issued in April 2018 clearly states that the government does not support the trade of such currencies; rather, transactions involving such assets should be reported. ${ }^{7}$ The Federal Board of Revenue and Federal Investigation Agency have taken legal action against Pakcoin as well as globally recognized currencies such as OneCoin and Bitcoin (Khan, 2017), charging them with tax evasion and money laundering.

It is, however, essential for the central bank to acknowledge that cryptocurrencies are a rapidly growing global phenomenon and that the National Financial Inclusion Strategy must start paying attention to such drastic global changes. Measures that the SBP could take to reduce the risks associated with these currencies is to classify ICOs and bring them under the regulation of the Securities and Exchange Commission of Pakistan (SECP) by categorizing them as Hacker and Thomale (2018) advise. They suggest making a clear distinction among types of currency, that is, assets commonly used for the exchange of goods, investment and utility tokens.

\footnotetext{
${ }^{7}$ http://www.sbp.org.pk/epd/2018/FEC3.htm
} 
Simply put, ICOs should be regulated as IPOs whereas tokens can be regulated as securities.

Two pathways for regulation could also be adopted to clarify these differences. The first is the disclosure of the characteristics of cryptocurrencies through prospectus regulation, which is governed by the SECP, and using these to obtain all the information necessary, which might otherwise be omitted, thus creating a safe, stable harbor for investors. The second regulatory track the SBP could adopt is to try to become part of an international convention for cryptocurrencies and strive for collective efforts with similar countries where implementation strategies need to be devised to centralize all regulatory efforts (Hacker \& Thomale, 2018).

The SBP could also follow the example set by Poland where cryptocurrencies are now subject to different categories of contract law, including private or company law. Once specified that cryptocurrencies do not fall in the category of financial instruments and are not an alternative form of payment, but rather personal belongings, the revenues from cryptocurrencies - primarily capital gains - could be taxed as personal income (see Ruminski \& Lichnowska, 2016). Taking such a step would help the government track how the public is using Bitcoin.

\section{Going Beyond the Currency: Further Uses of DLT and Blockchain}

The rise of cryptocurrencies has brought DLT and blockchain technology into the limelight. Around the world, these technologies are now being used to help improve people's lives. This section discusses different ways in which Pakistan could adopt and use this technology similar to other countries, with a view to improving governance and providing greater security and transparency in transactions.

As recent developments have shown, the application of this technology in the field of microfinance can help provide access to banking services and lead to greater financial inclusion (Baruri, 2016). Using digital accounts, lending transactions can take place on a platform backed by blockchain technology, which makes banking quicker and allows for lower banking costs, making it highly efficient and attractive for the unbanked in developing countries. Project Glass is one such blockchain startup that has the potential to grow because it will be able to reduce bank transaction costs for small and medium enterprises (SMEs). Similarly, Moeda is gaining attention as a microfinance platform linking investors to businesses in different parts of Brazil; it has been able to raise over $\$ 20$ million in an ICO 
(Schiller, 2018). BC Finance, in collaboration with a Japanese software house, is developing and implementing a peer-to-peer service for borrowers in Myanmar (Gilmore, 2016).

While these efforts are being made by private individuals, governments, such as that of Singapore, have also shown an interest in developing blockchain solutions to bank the unbanked (Bermingham, 2017). Pakistan has seen great benefits due to the growth of microfinance banking. However, if such a system was made available to the unbanked, with lower lending and banking transaction costs, it could help boost the microfinance and SME sector beyond the capacity of traditional banking, thereby improving the quality of life and helping channel entrepreneurship in both rural and urban areas.

Another application of blockchains and DLT is the digital identification system (DIS), used across the world. With the increase in use of online accounts for different activities, there has been a significant increase in identity fraud, where people have lost personal information as well as great sums of money and other assets. What the DIS does is prevent thirdparty access to people's personal information while allowing them full access to all services, like regular users. Some companies are now ensuring personal data security by employing blockchain technology and using cryptographic hashes to authenticate users without the information leaving a person's device. This enables them to decentralize personal information, similar to an ID card: a user's identity is safe as long as his or her personal devices are secure (Chester, 2017).

The Pakistan government could use such a system as part of the National Database and Registration Authority and Verisys systems to ensure that people feel safe in a digital environment. This could also help in data integration, bringing together physical and intellectual assets, thereby increasing transparency and reducing red tape in the economy. Moreover, such a digital system would allow the government to keep track of individuals' assets, enabling it to better protect their rights.

Blockchain and DLT technology can also be used to help developing countries such as Pakistan develop and improve their democratic processes, such as voting. While digital voting systems are being used all over the world - Estonia is one of the pioneers that implemented the technology in 2005 - such systems can be risky. Given the high replacement cost of the technology and lack of trust in the process (Penn Wharton Public Policy 
Initiative, 2017), a more transparent, efficient and trustworthy system needs to be developed.

The application of DLT and blockchain technology could help do so, although very little attention is being paid to this application. In Pakistan, where the electoral process is heavily criticized for inefficiency and corruption, adopting such a system would not be as costly in the long run and would help improve the democratic process. The system would operate such that the Blockchain protocol is designed by the Election Commission of Pakistan, which would set rules for the electoral process. The system would be used to log in each citizen and verify his or her identity, after which the votes would be recorded and counted by a central authority (the Election Commission of Pakistan). This would help prevent illegitimate voters from voting and create greater transparency in the system (Boucher, 2016).

One problem that has had a spiraling effect on Pakistan's economy is its energy crisis. While its governments have tried to reduce the shortfall in supply, the crisis is far from being resolved. Incorporating blockchain technology has the potential to help eliminate the added costs and delays in payment that have created "circular debt". The peer-to-peer electricity sharing system was first used in New York in April 2016 through Bitcoin. At present, several different platforms are being developed to eliminate the intermediary in this transaction, such as Wien Energie in Austria, Innogy in Germany and Electron in Britain (Basden \& Cottrell, 2017).

Similarly, land registry systems based on blockchain technology are now widely accepted and have been adopted by many countries. The UK has been testing the HM Land Registry and will soon make it fully functional, while Georgia has taken the lead by implementing its own system in February 2017, where it has registered over 100,000 documents. The Ukraine has entered into a partnership with a Blockchain provider to make its real estate sector more attractive to foreign investors by reducing corruption and fraud through a robust digital system (Osbourne Clarke, 2018).

The Government of Punjab digitized its land registry systems at the end of 2017 as an effort toward a more transparent system (World Bank, 2017). However, following the example set by countries such as the UK and Georgia, incorporating DLT in such a system could help improve it further and create a channel for the elimination of land mafias, helping enforce property rights. The Pakistani government should incorporate Blockchain technology as part of land reforms and partner with a Blockchain provider to implement a more effective land registry based on DLT and blockchain 
technology. This should be done for all parts of Pakistan, rural and urban, since it would improve the enforcement of property rights, reduce corruption and improve investor confidence.

Foreign aid is often lost at the hand of corrupt officials. According to UN Secretary General Ban Ki-moon, as much as 30 percent of development aid is lost to corruption. Using biometric data, systems can be designed to distribute all sorts of aid, especially food, to recipients, based on a blockchain system that records all transactions, making the system more transparent. This was implemented in 2017 when Syrian refugees in Jordan used retinal scans to pay for their food instead of money, which was done as part of the World Food Programme's aid. Pakistan could use a similar system for various aid distribution programs under international organizations such as UN as well as for local programs by government and private organizations (Bacchi, 2017).

\section{Conclusion}

In a rapidly growing digitized world, organizations need to keep up with the increased efficiency and productivity provided by highly advanced technologies. The increasing popularity of cryptocurrencies is an indicator of the inability of the global financial system to cater to people's needs and concerns, especially in the aftermath of the 2007 financial crisis. Technology has always preceded regulation, making regulatory options more complicated. There is therefore a need for regulators to meet this technological challenge and take a proactive approach to harnessing this complex modern technology.

The DLT adopted by cryptocurrencies has numerous uses that could reap multiple long-term benefits, especially for developing economies. The Blockchain market is predicted to grow from $£ 160.5$ million in 2016 to $£ 1.7$ billion by 2021 (Research and Markets, 2018) and it has the capacity to be used as a regulatory tool for achieving public policy goals. Regulators in Pakistan must recognize the importance of this technological breakthrough and join global efforts to regulate the riskier aspects of cryptocurrencies while adopting DLT and Blockchain for their numerous productive uses. 


\section{References}

Bacchi, U. (2017, June 21). UN glimpses into blockchain future with eye scan payments for refugees. Reuters. Retrieved from www.reuters.com/ article/us-un-refugees-blockchain/u-n-glimpses-into-blockchainfuture-with-eye-scan-payments-for-refugees-idUSKBN19C0BB

Barrat, M. J. (2012). Silk Road: Ebay for drugs. Addiction, 107(3), 683.

Baruri, P. (2016). Blockchain powered financial inclusion [Presentation]. Retrieved from http:/ / pubdocs.worldbank.org/en/710961476811913780/Session5C-Pani-Baruri-Blockchain-Financial-Inclusion-Pani.pdf

Basden, J., \& Cottrell, M. (2017, March 27). How utilities are using Blockchain to modernize the grid. Harvard Business Review. Retrieved from https://hbr.org/2017/03/how-utilities-are-usingblockchain-to-modernize-the-grid

Ben-Sasson, E., Chiesa, A., Genkin, D., Tromer, E., \& Virza, M. (2013). SNARKs for C: Verifying program executions succinctly and in zero knowledge. In R. Canetti \& J. A. Garay (Eds.), Advances in Cryptology-CRYPTO 2018 (pp. 90-108). Berlin: Springer.

Bermingham, F. (2017, November 15). Hong Kong-Singapore blockchain trade platform to go live in 2019. Global Trade Review. Retrieved from https://www.gtreview.com/news/asia/hong-kongsingapore-blockchain-project-to-go-live-in-2019/

Bonneau, J., Miller, A., Clark, J., Narayanan, A., ... Felten, E. W. (2015). SoK: Research perspectives and challenges for bitcoin and cryptocurrencies. In 2015 IEEE symposium on security and privacy: Proceedings (pp. 104-121). Los Alamitos, CA: IEEE Computer Society.

Boucher, P. (2016). What if blockchain technology revolutionized voting? Scientific Foresight Unit, European Parliamentary Research Service. Retrieved from http://www.europarl.europa.eu/ RegData/etudes/ATAG/2016/581918/EPRS_ATA(2016)581918_ EN.pdf 
Bradbury, D. (2013, July 30). Bitcoin industry leaders launch DATA, a selfregulatory body for digital currencies. Coindesk. Retrieved from http:/ / www.coindesk.com/bitcoin-industry-leaders-launch-dataa-self-regulatory-body

Bray, H. (2015, April 7). When hackers cripple data, police departments pay ransom. Boston Globe. Retrieved from www.bostonglobe.com/ business/2015/04/06/tewksbury-police-pay-bitcoin-ransomhackers/PkcE1GBTOfU52p31F9FM5L/story.html

Brezo, F., \& Bringas, P. G. (2013). Issues and risks associated with cryptocurrencies such as Bitcoin. In L. Berntzen \& P. Dini (Eds.), SOTICS 2012: The second international conference on social ecoinformatics (pp. 20-26). Wilmington, DE: IARA.

Bryans, D. (2014). Bitcoin and money laundering: Mining for an effective solution. Indiana Law Journal, 89(1), Article 13.

Buck, J. (2017, August 18). Bitcoin rise due to global currency crises, accessibility: Analysis. Cointelegraph. Retrieved from https://cointelegraph.com/news/bitcoin-rise-due-to-globalcurrency-crises-accessibility-analysis

Chester, J. (2017, March 3). How the blockchain will secure your online identity. Forbes. Retrieved from https://www.forbes.com/sites/ jonathanchester/2017/03/03/how-the-blockchain-will-secureyour-online-identity /\#587726335523

CNBC. (2018, December 15). US prosecutors move to cash in on $\$ 8.5$ million in seized bitcoin. CNBC. Retrieved from https://www.cnbc.com/ 2017/12/15/us-prosecutors-move-to-cash-in-on-8-point-5m-inseized-bitcoin.html

Davidson, S., De Filippi, P., \& Potts, J. (2016). Disrupting governance: The new institutional economics of distributed ledger technology. Retrieved from https://dx.doi.org/10.2139/ssrn.2811995

Davies, G. (2010). History of money. Cardiff: University of Wales Press.

Dibbell, J. (2002, January 1). In gold we trust. Wired. Retrieved from https://www.wired.com/2002/01/egold/ 
Europol. (2014, November 7). Global action against dark markets on Tor network [Press release]. Retrieved from www.europol.europa.eu/ newsroom/news/global-action-against-dark-markets-tor-network

Fernandez, C. M. (2012). Challenges and opportunities of online entertainment. In Proceedings of the 8th international conference on Internet, law and politics. Universitat Oberta de Catalunya, Barcelona, 9-10 July 2012 (pp. 199-209). Barcelona: Huygens Editorial.

Financial Crimes Enforcement Network. (2013, March 18). Application of FinCEN's regulations to persons administering, exchanging, or using virtual currencies. United States Department of the Treasury. Retrieved from https://www.fincen.gov/resources/statutesregulations/guidance/application-fincens-regulations-personsadministering

Foley, S. (2013, November 28). E-gold founder backs new Bitcoin rival. Financial Times. Retrieved from https://www.ft.com/content/ f7488616-561a-11e3-96f5-00144feabdc0

Garber, L. (2014). Government officials disrupt two major cyberattack systems (News Brief). Retrieved from Computer, Issue 47 (7), 16-21. DOI: 10.1109/mc.2014.189.

'Germany plans tax on bitcoin after virtual currency recognized as "private money".' (2013, August 19). Telegraph. Retrieved from https://www.telegraph.co.uk/finance/globalbusiness/10252383 /Germany-plans-tax-on-bitcoin-after-virtual-currency-recognisedas-private-money.html

Gilmore, S. (2016, July 25). Myanmar microfinance could see fintech first. Myanmar Times. Retrieved from https://www.mmtimes.com/ business/technology/21551-myanmar-microfinance-could-seefintech-first.html

Grinberg, I. (2012). The battle over taxing offshore accounts. UCLA Law Review, 60, 304-322.

Gupta, N. (2018, January 4). Singapore and blockchain technology - a beginner's guide. Zuu Online. Retrieved from https:/ / zuuonline.sg/business/ fintech/this-is-how-singapore-is-supporting-blockchain-technologydevelopment/ 
Hacker, P., \& Thomale, C. (2018). Crypto-securities regulation: ICOs, token sales and cryptocurrencies under EU financial law. De Gruyter, 15(4), 645-696.

Harvey, C., \& Tymoigne, E. (2015, March 1). Do cryptocurrencies such as Bitcoin have a future? Wall Street Journal. Retrieved from https://www.wsj.com/articles/do-cryptocurrencies-such-asbitcoin-have-a-future-1425269375

He, D., Habermeier, K., Leckow, F., Haksar, V., ... Verdugo-Yepes, C. (2016). Virtual currencies and beyond: Initial considerations (Staff Discussion Note No. 16/3). Washington, DC: International Monetary Fund.

Hern, A. (2018, January 17). Bitcoin's energy usage is huge - we can't afford to ignore it. Guardian. Retrieved from https://www.theguardian.com/technology/2018/jan/17/bitcoin -electricity-usage-huge-climate-cryptocurrency

Hileman, G., \& Rauchs, M. (2017). 2017 Global cryptocurrency benchmarking study. Cambridge: Cambridge Centre for Alternative Finance.

Hu, Y., Manzoor, A., Ekparinya, P., Liyanage, M., ... Ylianttila, M. (2017). Distributed delay-tolerant payment with blockchains. Retrieved from https://research.csiro.au/ng/research/network-measurementmodelling/distributed-delay-tolerant-payment-blockchains /

Husain, T. (2017, November 20). Is Bitcoin the future for Pakistan? Express Tribune. Retrieved from https://tribune.com.pk/story/1563057/2financial-innovation-bitcoin-future-pakistan/

Jacobs, E. (2011). Bitcoin: A bit too far? Journal of Internet Banking and Commerce, 16(2), 1-4.

Khan, M. Z. (2017, May 25). FBR goes after bitcoin traders. Dawn. Retrieved from https://www.dawn.com/news/1335184

Leary, K. (2017, October 2). This country could soon make Bitcoin its official currency. World Economic Forum. Retrieved from https://www.weforum.org/agenda/2017/10/this-latin-americancountry-could-adopt-bitcoin-as-an-official-currency/ 
Lehdonvitra, V. (2016, November 21). The blockchain paradox: Why distributed ledger technologies may do little to transform the economy. Oxford Internet Institute. Retrieved from www.oii.ox.ac.uk/blog/ the-blockchain-paradox-why-distributed-ledger-technologies-maydo-little-to-transform-the-economy /

Leising, M. (2018, January 30). US regulators subpoena CryptoExchange Bitfinex, Tether. Bloomberg. Retrieved from www.bloomberg.com/ news/articles/2018-01-30/crypto-exchange-bitfinex-tether-said-toget-subpoenaed-by-cftc

Leong, R., \& Chavez-Dreyfuss, G. (2018, May 14). Fed's Bullard says cryptocurrencies only adding to tangled market. Reuters. Retrieved from https://www.reuters.com/article/us-usa-fed-bullardcryptocurrencies/feds-bullard-says-cryptocurrencies-onlyadding-to-tangled-market-idUSKCN1IF1TA

Lufkin, B. (2017, October 19). Could Estonia be the first 'digital' country? BBC. Retrieved from http://www.bbc.com/future/story/20171019could-estonia-be-the-first-digital-country?

Marian, O. (2013). Are cryptocurrencies super tax havens? Michigan Law Review First Impressions, 112, 38-48.

Martin (2017, October 12). Bitcoin passes $\$ 5,000$ to hit fresh all-time high. Business Insider. Retrieved from http://uk.businessinsider.com/ bitcoin-price-5000-dollars-all-time-high-2017-10?utm_content=buffer debb5\&utm_medium=social\&utm_source=facebook.com\&utm_ca mpaign=buffer-ti

Maurer, B. M. (2011). Money nutters. Economic Sociology - The European Electronic Newsletter, 12(3), 5-12.

Mclean, R. (2016, February 17). Hospital pays bitcoin ransom after malware attack. CNN. Retrieved from http://money.cnn.com/ 2016/02/17/technology/hospital-bitcoin-ransom/index.html

Mearian, L. (2018, April 2). Bitcoin mining leads to an unexpected GPU gold rush. Computerworld. Retrieved from www.computerworld.com/ article/3267744/bitcoin-mining-leads-to-an-unexpected-gpu-goldrush.html 
Megaw, N. (2018, February 8). ECB board member calls for global clampdown on cryptocurrencies. Financial Times. Retrieved from https://www.ft.com/content/f1a09c38-0c9d-11e8-8eb742f857ea9f09

Meredith, S. (2017, December 15). Bitcoin buyers should be prepared to lose all their money, top UK regulator warns. CNBC. Retrieved from https:/ / www.cnbc.com/2017/12/15/bitcoin-buyers-should-beprepared-to-lose-all-their-money-top-uk-regulator-warns.html

Middlebrook, S. T., \& Hughes, S. J. (2014). Regulating cryptocurrencies in the United States: Current issues and future directions. William Mitchell Law Review, 40(2), 813-848.

Miller, H. (2017, 10 October). Welcome to Crypto Valley. Bloomberg Businessweek. Retrieved from https://www.bloomberg.com/ news/articles/2017-10-10/welcome-to-crypto-valley

Montag, A. (2018, May 1). Warren Buffett explains one thing people still don't understand about bitcoin. CNBC. Retrieved from https://www.cnbc.com/2018/05/01/warren-buffett-bitcoin-isntan-investment.html

Nelson, A. (2018, February 1). Cryptocurrency regulation in 2018: Where the world stands right now. Bitcoin Magazine. Retrieved from https:/ / bitcoinmagazine.com/articles/cryptocurrencyregulation-2018-where-world-stands-right-now /

Omohundro, S. (2014). Cryptocurrencies, smart contracts, and artificial intelligence. AI matters, 1(2), 19-21.

Osbourne Clarke. (2018). Blockchain and land registries records of the future. Retrieved from http://www.osbourneclarke.com/insights/ blockchain-and-land-registries-records-of-the-future /

Penn Wharton Public Policy Initiative. (2017). The business of voting: Market structure and innovation in the election technology industry. Philadelphia: Author. 
Pollock, D. (2018, February 20). Singapore's government blockchain experiment is a road to regulatory understanding. Cointelegraph. Retrieved from https:/ / cointelegraph.com/news/singapores-governmentblockchain-experiment-is-a-road-to-regulatory-understanding

Popken, B. (2018, February 3). Bitcoin loses more than half its value amid cryptocrash. NBC News. Retrieved from www.nbcnews.com/tech/ internet/bitcoin-loses-more-half-its-value-amid-crypto-crashn844056

Popper, N. (2017, December 7). Bitcoin's price has soared. What comes next? New York Times. Retrieved from https:/ / www.nytimes.com/ 2017/12/07/technology/bitcoin-price-rise.html

Research and Markets. (2018). Blockchain in telecom market by provider application, organization size and region - global forecast to 2023. Retrieved from https://www.researchandmarkets.com/research/ 383qcp/blockchain_in?w=4

Roberts, J. J. (2017, December 4). Bitcoin futures could trigger a Lehman-style collapse, billionaire warns. Fortune. Retrieved from http:/ / fortune.com/2017/12/04/bitcoin-futures/

Ruminski, A., \& Lichnowska, K. (2016, October 12). Blockchain: A Polish perspective. University of Oxford, Faculty of Law. Retrieved from https:/ /www.law.ox.ac.uk/business-law-blog/blog/2016/10/ blockchain-polish-perspective

Satoshi Nakamoto. (2008). Bitcoin: A peer-to-peer electronic cash system. Retrieved from https://bitcoin.org/bitcoin.pdf

Schiller, B. (2018, December 2). Can the world's underbanked leapfrog on to a new blockchain financial system? Fast Company. Retrieved from https://www.fastcompany.com/40524015/can-the-worldsunderbanked-leapfrog-on-to-a-new-blockchain-financial-system

State Bank of Pakistan. (2016). Soundness and efficiency of financial market infrastructure. In Financial Stability Review (Chap. 5). Retrieved from http://www.sbp.org.pk/FSR/2016/pdf/Chap-5.pdf 
Tapscott, D., \& Tapscott, A. (2016). Blockchain revolution: How the technology behind Bitcoin and other cryptocurrencies is changing the world. New York: Penguin.

US Department of Justice. (2007). Digital currency business E-Gold indicted for money laundering and illegal money transmitting [Press Release]. Retrieved from http://www.justice.gov/opa/pr/2007/April/ 07_crm_301.html

van Saberhagen, N. (2013). CryptoNote v 2.0. Retrieved from cryptonote.org/ whitepaper.pdf

Wagstaff, J. (2014, February 28). Mt. Gox bitcoin debacle: Huge heist or sloppy glitch? Reuters. Retrieved from https:/ /www.reuters.com/article/ us-bitcoin-mtgox-heist/mt-gox-bitcoin-debacle-huge-heist-orsloppy-glitch-idUSBREA1R0Y720140228

Wildau, G. (2017, September 4). China central bank declares initial coin offerings illegal. Financial Times. Retrieved from www.ft.com/ content/3fa8f60a-9156-11e7-a9e6-11d2f0ebb7f0?mhq5j=e5

World Bank. (2017, September 20). In Pakistan and beyond, land records get a digital upgrade. Retrieved from http://www.worldbank.org/en/ news/feature/2017/09/20/in-pakistan-and-beyond-land-recordsget-a-digital-upgrade

Yoo, T. (2017, October 16). Here's fintech's secret pitch to the RBA to create an Australian dollar cryptocurrency. Business Insider. Retrieved from https://www.businessinsider.com.au/auscoin-fintechs-secretpitch-to-the-rba-to-create-an-australian-dollar-cryptocurrency-201710\#Z2eILG24fZWtWGoM.99

Zhao, W. (2018, February 5). Singapore Airlines to launch blockchain-based loyalty wallet. Coindesk. Retrieved from https://www.coindesk.com/ singapore-airlines-launch-blockchain-based-loyalty-wallet 